\title{
Música, Metáfora e Conceitos Estéticos
}

NICK ZANGWILL ${ }^{1}$

HULL UNIVERSITY (n.zangwill@hull.ac.uk)

8

realismo estético aplicado à arte da música é, no mínimo, a ideia de que a música tem propriedades estéticas, as quais são, em algum sentido, "independentes da mente" (mind independent) e que, na experiência musical e no discurso sobre a música, pensamos nesta arte como possuidora de tais propriedades estéticas. Além disso, a música não apenas possui propriedades estéticas, ela é projetada para tê-las; mas isso não será abordado neste artigo. Uma ideia mais controversa poderia ser a de que os sons que constituem a música têm propriedades estéticas "independentes da mente" e que ao experienciarmos a música e ao falarmos sobre ela atribuímos propriedades estéticas aos sons. Contudo, irei ignorar essa tese mais controversa sobre os sons que constituem a música.

O presente artigo estará focado nos conceitos estéticos. Uma parte importante do realismo estético é a ideia de que os conceitos estéticos designam propriedades estéticas. No caso da música, o realista estético defende que os conceitos estéticos que aparecem nas experiências e nos juízos estéticos em muitos casos designam propriedades estéticas da música (e talvez dos sons que a constituem). Algumas vezes erramos. Mas quando acertamos, empregamos conceitos estéticos para representar propriedades estéticas que a música possui. Entretanto, tem sido discutido - principalmente por Roger Scruton (1974; 1997) - que existem problemas na compreensão do realista estético acerca da relação entre conceitos estéticos e conceitos não-estéticos. Acredita-se que esses problemas sejam gerados pelo uso das metáforas na descrição da música e da experiência musical. Abordarei aqui algumas questões levantadas a partir desse fato, em resposta a

1 Tradução: Ísis Biazioli e Said Tuma. Revisão: Danielle Bambace e Mário Videira. 
objeções formuladas por Malcolm Budd, e veremos que o realismo estético precisa ser desenvolvido numa certa direção. Neste artigo procurarei desenvolver e defender o realismo estético, ao invés de argumentar contra visões não-realistas.

\section{§1. Realismo e a Consideração Causal}

$\S 1.1$ Comecemos pelo fato de que é habitual descrever a música em termos de emoção, movimento e altura. Aquilo que podemos chamar de Tese Estético-Metafórica (Aesthetic Metaphor Thesis) é a tese na qual tais descrições são quase sempre metafóricas - não são descritas nem estão implicadas nenhuma emoção, movimento ou altura reais. Em vez disso, descrevemos a música metaforicamente, usando palavras que não se aplicam literalmente a ela. Isto é, embora descrevamos a música usando palavras para emoção, movimento ou altura, não é porque emoções, movimentos e alturas reais estejam na

64 música, ou porque a música esteja em alguma relação com emoções, movimentos ou alturas reais. É claro que, algumas vezes, ao descrever os sons como "alto" ou "baixo", poderíamos querer dizer literalmente alto como em uma montanha ou baixo como em um vale; mas isto não é usual (o que explica a restrição "quase sempre" acima). Esta tese se estende a muitos outros tipos de descrições da música, que também são metafóricas ou pelo menos não consideram somente $o$ significado literal primário das palavras. Por exemplo, quando descrevemos uma música como "delicada", não é porque ela seja delicada no mesmo sentido em que dizemos que uma casca de ovo é delicada. A música não pode ser quebrada. Quase todas as descrições da música, sejam de ouvintes comuns ou de críticos profissionais, contêm muitas metáforas.

Não irei propor nenhuma teoria sobre a metáfora no presente artigo (cf. ZANGWILL, 2014). Por mais correta que fosse uma tal teoria, não pode haver um critério geral para a metáfora; identificar os usos metafóricos dependerá do termo literal em questão. Para os nossos propósitos, será o bastante que os significados literais primários de palavras como "raivoso" não estejam em jogo quando falarmos da música, e isto pelas seguintes razões: os sons não podem ficar com raiva 
de nada, sons não têm sentimentos, e a raiva dos sons não é racionalizada de distintas maneiras tal como a raiva usual o é. Todas essas razões são igualmente aplicáveis à descrição de nuvens como "raivosas". A "raiva" aplicada literalmente à música não é mais plausível do que quando aplicada às nuvens. Assim, a descrição da música como "raivosa" é uma descrição metafórica.

Não estou preocupado em argumentar contra as concepções "literalistas" que negam a dimensão metafórica das descrições estéticas em termos de emoção, movimento, altura ou delicadeza. Já abordei esse tema em outros trabalhos (ZANGWILL, 2004, p. 29-43; 2007, p. 391-400). Neste artigo eu assumo que essa "batalha" já foi vencida. Por "literalismo" entendo aquele ponto de vista em que os significados literais de palavras como "delicado" ou "raivoso" aplicam-se à música no mesmo sentido em que se aplicam às cascas de ovos ou às pessoas. $^{2}$

Nós também fazemos descrições estéticas literais da música quando a descrevemos como "bela" ou "elegante", mas no presente artigo o meu foco estará nas descrições estéticas não-literais.

$\S 1.2$ Realistas e não-realistas têm interpretações e explicações diferentes para a Tese Estético-Metafórica (Aesthetic Metaphor Thesis). A concepção particular do realismo estético que eu defendo é que quando descrevemos a música em termos de emoção, movimento, altura ou delicadeza, estes termos são descrições metafóricas de

2 Portanto, alguém que postule significados literais secundários de "triste" ou "delicado", que se diz aplicar à música, mas não a pessoas ou cascas de ovos, é classificado como um não-literalista, nesse sentido (Cf. DAVIES, 1994, p. 162-164). Critiquei essa concepção em ZANGWILL (2007). Agora, observo apenas que um teórico do "significado literal secundário" precisará de muita mágica para criar significados literais secundários sempre que uma palavra é aplicada à música sem nenhum precedente. Somos criativos em nossas descrições estéticas da música usando significados literais (primários) de palavras que temos disponíveis. Uma lista dicionarizada e fossilizada de significados secundários não pode dar conta disso. 
propriedades estéticas da música. Tais propriedades estéticas metaforicamente descritas são chamadas algumas vezes de propriedades estéticas "substantivas" ("substantive") ou "densas" ("thick"), porque as descrições delas vão além de uma descrição rasa de algo como "belo", "feio", ou como possuidora de "mérito estético" ou "demérito estético"3. Exemplos de outras propriedades substantivas são "graça", "robustez", "elegância" e "equilíbrio". Algumas descrições substantivas são metafóricas (tal como "equilibrado") e algumas (tal como "elegante") não o são. Mas para o realista estético, o ponto principal das descrições substantivas é descrever as propriedades estéticas substantivas de algo. ${ }^{4}$

Dada a Tese Estético-Metafórica (Aesthetic Metaphor Thesis), o realista estético faz uma distinção fundamental entre os conceitos estéticos e os conceitos não-estéticos de tristeza e delicadeza. Isto porque as crenças sobre as propriedades estéticas substantivas da música são constituídas em parte por 66 conceitos que representam ou que se referem àquelas propriedades. Porém, conceitos não-estéticos de tristeza e delicadeza representam ou se referem a propriedades nãoestéticas comuns, tais como a tristeza das pessoas ou a delicadeza das cascas de ovos. Assim, os conceitos estéticos e não-estéticos de tristeza e delicadeza são diferentes. É preciso ressaltar que esta não é uma questão sobre o significado (meaning) da palavra: o significado é o mesmo nas descrições

${ }^{3}$ Ver os capítulos 1 e 2 (in ZANGWILL, 2001), onde defendo a concepção de que as propriedades substantivas (substantive properties) são modos de ser belo ou feio. Ver também (ZANGWILL, 2013).

${ }^{4}$ Uma ideia não-realista proeminente é a de que a experiência musical envolve imaginar emoção, movimento, altura ou delicadeza. As concepções de Scruton (1997) e Levinson (1996; 2006) são desse tipo. Para uma discussão crítica de Scruton, cf. Zangwill (2010a, p. 91-104). Outras concepções não-realistas relacionam a música com emoções reais (e não apenas imaginadas) em artistas ou ouvintes. Neste artigo meu foco é o realismo, não suas correntes rivais, embora na seção §3.4.1 eu forneça uma explicação peculiar acerca da adequação metafórica que está disponível para as teorias da imaginação. 
estéticas e não-estéticas, enquanto os conceitos empregados são diferentes.

Podemos distinguir o significado de uma palavra (ou frase) a partir daquilo que uma pessoa quer dizer usando uma palavra (ou frase). Quando Romeu diz: "Julieta é o sol", a palavra "sol" significa o mesmo que em: "O sol está brilhando sobre as árvores", mas existe um sentido no qual a pessoa Romeu quer dizer algo diferente ao usar a mesma palavra. Do mesmo modo, as palavras "triste" ou "delicado" significam o mesmo dentro e fora das descrições musicais, apesar de existir um sentido no qual é diferente o que a pessoa quer dizer ao usar a palavra com o mesmo significado. Isto ocorre porque os conceitos que aparecem nos pensamentos e nas experiências das pessoas ao descreverem a música como "triste" ou "delicada" são bastante diferentes daqueles conceitos que figuram em seus pensamentos e experiências ao descreverem pessoas como "tristes" e cascas de ovos como "delicadas". ${ }^{5}$

Alguns filósofos da linguagem negaram a possibilidade de um pensamento que não se expresse em linguagem. Quando isto não é um franco behaviorismo na sua forma mais implausível, trata-se de uma afirmação inquestionável de que muito do conteúdo do pensamento é afetado pela linguagem e que muitos tipos de pensamentos sofisticados somente são possíveis devido à linguagem. De todo modo, permanece uma questão em aberto: se existem tipos de pensamentos cuja expressão linguística é problemática. Não é particularmente controverso que existam muitas sensações e emoções que podem ser pensadas, mesmo sendo difíceis de serem descritas. É este tipo de espaço intelectual que um realista estético pode ocupar.

§1.3 Uma vez que tenhamos feito uma firme distinção entre conceitos estéticos e não-estéticos, surge a questão: qual a conexão existente entre eles? Isto pode ser colocado como uma questão sobre a posse de um conceito: para o realista, qual

${ }^{5}$ Sigo, de maneira geral, a explicação davidsoniana (Cf. DAVIDSON, 1984, p. 262-263). Para minhas próprias considerações acerca dessa concepção, cf. Zangwill (2013). 
é a conexão entre ser capaz de pensar e escutar música como possuindo a propriedade estética substantiva da tristeza (a qual descrevemos metaforicamente usando a palavra que designa a emoção "triste"), e ser capaz de pensar sobre emoções comuns de tristeza, às quais o termo ordinariamente se refere? Iremos utilizar subscritos para indicar quando estamos falando sobre uma característica estética $\mathbf{E}_{\mathbf{E}}$ que é descrita metaforicamente ou uma característica não-estética comum. Por exemplo, a tristezaE da música e a tristeza ${ }_{N E}$ de uma pessoa poderiam ser descritas, em língua portuguesa, pela palavra "triste". As duas propriedades são muito diferentes, ao menos para o realista estético. Mas existe uma preocupação natural: há alguma conexão entre elas? Certamente há alguma conexão. Se é assim, qual é esta conexão? O realista estético precisa abordar esta questão.

Uma ideia (ZANGWILL, 1991, p. 169-170, reimpresso em ZANGWILL, 2001) é que, embora os conceitos estéticos e 68 não-estéticos de delicadeza ou de tristeza sejam distintos, a posse do conceito estético seria causalmente dependente da posse do conceito não-estético. 0 que esta afirmação causal sugere é a necessidade de distinguir os dois conceitos sem afirmar que eles são completamente desconectados. Onde existe uma relação causal, coisas distintas estão amarradas. (Talvez o conceito de aparentar delicadeza ${ }_{\mathbf{N E}}$ seja um intermediário). Tal visão causal é uma consequência natural e talvez inevitável do realismo estético. Pois que outra ligação entre coisas distintas poderia haver?

Malcom Budd publicou dois tipos interessantes de críticas dessa concepção causal: um tipo que enfoca em conceitos; o outro, no uso metafórico da linguagem (BUDD, 2008 - cf. especialmente p. 177-179). Ele afirma, em primeiro lugar, que a concepção causal não pode oferecer nenhuma explicação e é, na verdade, incompatível com o fato de que não podemos possuir o conceito estético sem possuir o conceito não-estético. Em segundo lugar, Budd afirma que a relação causal é insuficiente para explicar o que diz respeito à descrição metafórica - em particular, a relação causal não explicaria porque aplicamos palavras para as propriedades não-estéticas de modo a descrever propriedades estéticas. Além disso, a relação causal não explicaria como os significados 
literais de palavras não-estéticas guiam suas aplicações metafóricas nas descrições estéticas. (Budd também rejeita a ideia de que as propriedades estéticas devem ser descritas metaforicamente, o que eu chamo de 'Tese da Metáfora Essencial' - Essential Metaphor Thesis. Não está claro que essa concepção seja essencial para o realismo estético, contudo, acredito que isto seja plausível de maneira independente. Eu discuto criticamente as contestações de Budd sobre aquela tese em outro artigo (ZANGWILL, 2011, p. 1-16), que suscita questões diferentes).

Não vou responder a essas objeções meramente no intuito de me defender contra as observações de Budd. Em vez disso, pretendo propor uma relação mais plena entre a posse do conceito estético e a descrição metafórica, a partir do ponto de vista realista - o que tem como consequência neutralizar as objeções de Budd. Meu objetivo principal é enriquecer o realismo e não me desviar das dificuldades. No que segue, irei tratar primeiramente dos conceitos estéticos e dos conceitos não-estéticos (na seção 2) e, então, abordarei o uso de palavras não-estéticas nas descrições estéticas metafóricas (na seção 3).

\section{§2. A Relação entre Conceitos Estéticos e Não- Estéticos}

§2.1 De acordo com a explicação causal, a posse do conceito não-estético de delicadeza (= "delicadeza ${ }_{\mathrm{NE}}$ ") é uma causa parcial da posse do conceito de delicadeza (= "delicadezaE"). Porém isto parece criar a possibilidade de posse do conceito estético sem o conceito não-estético. Conforme escreve Budd:

Zangwill não apenas falha ao explicar porque é que não se consegue apreender o conceito estético sem possuir o conceito não-estético, como também não parece haver nenhuma linha de pensamento plausível - ao menos, nenhuma que esteja baseada na conexão conceitual entre os conteúdos dos dois conceitos (uma vez que não se presume ser apenas um) (BUDD, 2008, p. 178).

0 desafio é que necessitamos de uma explicação que implique a ideia de que não podemos chegar a possuir o 
conceito estético de delicadeza (= "delicadeza") a menos que possuamos o conceito não-estético de (= delicadeza $\mathrm{NE}_{\mathrm{E}}$ "). A explicação causal do realista parece ser incompatível com esta impossibilidade. Se duas coisas são existências distintas e estão relacionadas causalmente, então uma pode existir sem a outra. Desse modo, se conceitos estéticos e não-estéticos são existências distintas causalmente relacionadas, então a reivindicação causal do realista parece ser incompatível com o fato de que uma pessoa não possa possuir o conceito estético sem também possuir o conceito não-estético.

§2.2 Uma sugestão poderia ser que, apesar dos conceitos serem diferentes e, por isso, não terem significados equivalentes, há, no entanto, de alguma maneira uma relação de vinculação analítica unidirecional entre as proposições que contêm os dois conceitos. Porém, a relação entre conceitos estéticos e não-estéticos que são expressos com a mesma palavra não parece ser desse tipo. Muitas esculturas 70 esteticamente delicadas são surpreendentemente robustas em um sentido físico e muitas esculturas fisicamente delicadas não são, de maneira alguma, esteticamente delicadas. Desta forma, proposições sobre delicadeza $a_{\mathrm{E}}$ não implicam analiticamente e nem são analiticamente implicadas por proposições sobre delicadeza $_{\mathrm{NE}}$ o que significa que esta sugestão não pode auxiliar o realista.

Outra sugestão poderia ser a de fortalecer a afirmação causal de modo que a relação entre a posse dos conceitos estéticos e não-estéticos seja uma relação do tipo parte-todo. Onde há relações parte-todo, não há identidade entre duas coisas - não obstante há laços necessários. Uma árvore não é idêntica ao seu tronco, e ainda assim existem relações condicionais necessárias entre o que acontece ao tronco e o que acontece com a árvore. Se você desloca o tronco, você desloca a árvore. Uma relação desse tipo poderia existir entre a posse dos dois conceitos. Talvez a posse do conceito de delicadeza ${ }_{\mathrm{NE}}$ seja parte daquilo que é a posse do conceito de delicadeza ${ }_{E}$. Tal visão parte-todo poderia sustentar a afirmação de que não é possível possuir o conceito de delicadeza $\mathrm{E}$ a menos que possuamos o conceito de delicadeza $a_{\mathrm{NE}}$, mesmo que esses conceitos não sejam idênticos. A ideia poderia ser que a posse do conceito estético é uma realização sofisticada, a qual se 
baseia e inclui a posse do conceito ordinário. No entanto, o problema é que onde o todo está presente, está também a parte. Desse modo, se o conceito estético se aplica a uma coisa, assim também se aplicaria o conceito não-estético. Mas, se tivermos algo esteticamente delicado, mas fisicamente robusto, o conceito estético se aplica, ao passo que o conceito nãoestético não poderia ser aplicado. Portanto, a sugestão partetodo é tão pouco promissora quanto a relação de vinculação analítica.

Uma terceira sugestão poderia ser a defesa de uma relação de constituição. Consideremos os seguintes pares de habilidades: a habilidade de andar e a habilidade de jogar futebol; a habilidade de jogar e apanhar coisas e a habilidade de fazer malabarismos; a habilidade de usar a linguagem e a habilidade de contar uma piada; a habilidade de produzir sons em um piano pressionando suas teclas e a habilidade de tocar uma sonata de Beethoven. Nestes casos a habilidade mais simples é parte constitutiva daquela mais complexa. Porém este não é um bom modelo para a relação entre conceitos estéticos e não-estéticos. Empregar o conceito estético deveria significar empregar o conceito não-estético que seria parte constitutiva deste. Porém, existem esculturas fisicamente robustas, mas esteticamente delicadas; desse modo o conceito estético se aplica, mas não o conceito não-estético. Portanto, o conceito estético não pode ser parcialmente constituído pelo conceito não-estético.

$\S 2.30$ que aprendemos com estas sugestões e a insuficiência delas é que a visão causal precisa ser desenvolvida numa certa direção. Perguntemos em primeiro lugar: como é possível que a posse de dois conceitos seja causalmente relacionada? 0 que isso significaria? Possuir um conceito é um certo tipo de capacidade ou habilidade - a capacidade ou a habilidade de ter estados mentais intencionais com certos conteúdos ${ }^{6}$. Tais capacidades ou habilidades conceituais possuem propriedades causais e podem ser adquiridas por processos causais. As duas opções padrão são: ou elas são

${ }^{6}$ Peter Geach (1957, p. 7) escreve: "conceitos (...) são capacidades exercidas em atos de julgamento". 
inatas ou são aprendidas. 0 ponto importante, contudo, é que a aquisição dos conceitos pode ser estruturada. Possuir um conceito pode ser uma condição causal para a posse de outro conceito.

Consideremos alguns exemplos de habilidades que se encontram em relação causal. Adultos que podem caminhar possuem essa habilidade como consequência causal de terem sido bebês que podiam engatinhar - mesmo que andar e engatinhar sejam habilidades distintas para os adultos. Um determinado adulto pode ser capaz de andar, mas não de engatinhar, devido a problemas nos joelhos. Do mesmo modo, a habilidade de ouvir pode ser uma condição causal da aquisição de muitas habilidades que são distintas da audição, as quais devemos possuir mesmo que já não sejamos mais capazes de ouvir. A habilidade de compor música poderia ser um exemplo. Não existe uma ligação estritamente necessária (podemos imaginá-la de outra forma), mas mesmo assim pode haver uma relação causal.

Habilidades conceituais podem estar nesse tipo de relação causal. Consideremos o aprendizado da matemática: existem conceitos matemáticos mais ou menos básicos, sendo que primeiramente são adquiridos os mais básicos. Por exemplo, talvez se aprenda a contar antes que se possa abordar ramos mais avançados da álgebra que não envolvam números. Ou então consideremos a mudança de uma teoria científica: possuímos novos conceitos com base na posse de conceitos antigos, e pode-se até mesmo vir a rejeitar aqueles antigos conceitos sem os quais não se poderia ter adquirido os conceitos novos. Por exemplo, as crianças possuem conceitos absolutos de "para cima" e "para baixo", e é plausível que a posse desses conceitos seja um pré-requisito causal para a aquisição de um conceito sofisticado e relativístico de direção. Nós poderíamos, em princípio, possuir os conceitos sofisticados sem nunca termos possuído os conceitos simples, mas isto é improvável para criaturas como nós. Sugiro que o realista estético possa defender que uma relação deste tipo exista entre os conceitos estéticos e não-estéticos de tristeza ou delicadeza: as habilidades conceituais são distintas, mas possuir, ou ter possuído, a habilidade conceitual não-estética, é uma condição causal para a posse da habilidade conceitual estética. Existe um 
caminho causal de um para o outro. Isto é, para criaturas como nós, em condições normais, a posse dos conceitos estéticos de delicadeza ou tristeza depende causalmente de possuir, ou de ter possuído, os conceitos não-estéticos de delicadeza e de tristeza.

§2.4 Esse modelo causal admite que seja realmente possível adquirir um conceito estético sem a posse do conceito não-estético: é exatamente isto o que Budd considerou questionável. A objeção de Budd pode ser respondida, pelo menos superficialmente, se aceitarmos aquilo que ele considerou como uma reductio. Porém ainda não ofereci ainda uma evidência positiva para o pensamento de que os conceitos estéticos e não-estéticos de tristeza ou de delicadeza estão relacionados tal como afirma a teoria causal. Além disso, nós poderímos imaginar: não há algo intuitivo no argumento de Budd de que precisamos possuir o conceito não-estético para podermos possuir o estético?

Proponho que se faça uma distinção entre conceitos estéticos determinados e conceitos estéticos gerais. Consideremos a propriedade estética que descrevemos como "delicadeza". Essa propriedade estética se manifesta ou se realiza de modo variável na música, na poesia, na pintura, nas nuvens e em muitas outras coisas. Todas podem ser casos de delicadeza. Agora, consideremos a delicadeza $\mathrm{E}_{\mathrm{E}}$ particular de algumas nuvens do tipo cirrus. Essa é uma propriedade estética determinada, e essa propriedade estética não é compartilhada pela música delicada ou pela poesia delicada, embora outras nuvens cirrus possam compartilhar essa propriedade.

0 realista pode admitir que a noção geral de delicadeza $a_{E}$ partilhada por coisas muito diferentes umas das outras, é uma noção que requer que tenhamos o conceito de delicadeza $_{\mathrm{NE}}$. É plausível que ser capaz de pensar naquele agrupamento de características estéticas determinadas dependa da compreensão do conceito não-estético, sem o qual a coleção das propriedades estéticas poderia parecer arbitrária.

O mesmo não é verdade para a delicadeza $\mathrm{E}_{\mathrm{E}}$ específica de uma coisa, tal como a delicadeza $\mathrm{E}_{\mathrm{E}}$ específica de uma nuvem 
cirrus $^{7}$. A visão do realista deveria ser que nós podemos ter o conceito daquele tipo específico de delicadeza ${ }_{\mathrm{E}}$ sem possuir o conceito ordinário de delicadeza $\mathrm{NE}_{\mathrm{NE}}$. Ev evidente que podemos ter um conceito correspondente à propriedade estética específica sem possuir o conceito não-estético ordinário de delicadeza, se considerarmos pessoas que têm experiências estéticas ricas com certas nuvens cirrus e suas propriedades estéticas específicas. Tais pessoas podem muito bem não ter pensado em usar a palavra "delicada" como um termo útil e apropriado para descrever as propriedades estéticas específicas dessas nuvens. Além disso, não há nenhuma razão para se pensar que tais pessoas estejam operando com o conceito não-estético. É por isto que existe muito a dito em favor do ponto de vista que considera uma diferenciação entre conceitos de propriedade estética determinada e conceitos não-estéticos ordinários, a não ser que o uso da palavra que normalmente expressa o conceito não-estético possa ser um modo conveniente de descrever aquilo ao qual o conceito estético determinado se 74 refere.

§2.5 Propriedades estéticas determinadas têm prioridade sobre propriedades estéticas mais gerais, a saber, da seguinte forma: as coisas têm propriedades estéticas determinadas em virtude das quais elas possuem as suas propriedades estéticas mais gerais. Por exemplo, algo pode ser belo em virtude de ser delicado (e isto, em virtude de ser delicado de um modo particular), do mesmo modo que algo pode ser colorido em virtude de ser vermelho (e isto, em virtude de ser escarlate). Além disso, nossa experiência das delicadezas mais determinadas de algo que encontramos na nossa experiência estética é, em termos explicativos, anterior à nossa compreensão de tipos mais gerais, tais como a

\footnotetext{
7 Não estou falando sobre o que às vezes é chamado de "tropos", mas sobre tipos exemplificados por aquela nuvem cirrus ou alguma como aquela. Um vaso delicado não possui essa propriedade de delicadeza, embora outra nuvem cirrus similar possa tê-la. Essas propriedades estéticas determinadas podem ser, mas não precisam ser, o que eu chamei em outra ocasião de propriedades estéticas totais, que são o conjunto de todas as propriedades estéticas de algo. Cf. ZANGWILL (2001), especialmente o capítulo 3.
} 
delicadeza. Isso não significa que não experienciemos propriedades estéticas mais gerais das coisas; pelo contrário, isso significa que experienciamos essas propriedades estéticas mais gerais em virtude de nossa experiência das propriedades estéticas mais determinadas. Nossa experiência musical básica é a de propriedades estéticas relativamente determinadas, e isto explica nossa experiência estética mais geral.

Devo admitir que tenho uma concepção metafísica bastante geral como uma espécie de pano de fundo, a qual se encaixa perfeitamente nessa concepção dos conceitos estéticos. Essa concepção metafísica é a de que o mundo (objetos e propriedades e tudo mais que possa existir) possui tanto propriedades determinadas quanto propriedades mais gerais. As coisas possuem propriedades determinadas (tais como cores e tamanhos específicos) quanto propriedades mais gerais (ser colorida ou ser maior do que um metro e meio). Contudo, as propriedades determinadas são metafisicamente fundamentais. Algo é um ser vivo em virtude de ser um mamífero, em virtude de ser um macaco, em virtude de ser um macaco específico. 0 mundo é tal como ele é de maneira geral em virtude de como ele é de maneira determinada ${ }^{8}$. Em alguma medida, existe um eco desse fato metafísico em nossas experiências e pensamentos. Nossa experiência perceptiva pode ser de algo colorido, de algo vermelho e de algo escarlate. Talvez, em nossas experiências perceptivas, sejamos incapazes de discriminar mais além, em direção a tipos ainda mais determinados de escarlate, embora as cores sejam, de fato, subdivididas de maneira mais sutil. Mesmo assim, o conteúdo de nossa experiência perceptiva é estruturado entre conteúdos mais ou menos determinados, mesmo que possa não existir nenhum conteúdo completamente determinado, do mesmo modo em que o próprio mundo possui propriedades completamente determinadas, as quais determinam suas propriedades mais gerais.

\footnotetext{
${ }^{8}$ Eu também acho que algo similar é verdadeiro acerca das propriedades precisas e vagas: algo pode ser vagamente laranja em virtude de ser precisamente vermelho.
} 
Nossas experiências estéticas acontecem de modo similar. Nós experimentamos os sons como belos e também experimentamos esses sons como delicados. Nós também experimentamos esses sons como sendo delicados de uma maneira musical, de um modo que uma cerâmica delicada não é - uma delicadeza musical. E nós também experimentamos os sons como sendo delicados de uma maneira particular: da maneira pela qual a Polonaise $n^{\circ} .12$ (em Si bemol Maior) de Chopin é delicada, chamando isso de delicadeza da Polonaise $n^{\circ}$. 12 de Chopin ${ }^{9}$. Nossa experiência musical é constituída por todas essas ao mesmo tempo, assim como nossa experiência perceptiva pode ser de algo colorido, vermelho e escarlate: tudo isso de uma só vez. Nesses dois casos, a experiência é estruturada. Nós experimentamos a beleza em virtude de experimentar a delicadeza, em virtude de experimentar a delicadeza musical, em virtude de experimentar a delicadeza musical da Polonaise $n^{\circ}$. 12 de Chopin. Sem essa experiência determinada de delicadeza não poderia haver outra 76 experiência estética. Essa experiência determinada é a experiência musical básica. E para ter essa experiência determinada não é suficiente possuir a noção ordinária de delicadeza, mesmo que a palavra para a delicadeza ordinária possa ser uma maneira útil para descrever a experiência musical em seu aspecto mais grosseiro e menos determinado.

$\S 2.6$ É necessário dizer que o conceito geral de delicadeza é a disjunção (talvez a disjunção infinita) de todas as concepções determinadas de delicadeza estética. Mas não está claro que podemos pensar em tais conceitos disjuntivos ou que eles possam figurar no conteúdo da experiência musical. E mesmo se pudermos, nós ainda podemos perguntar: o que todos os disjuntivos têm em comum? 0 que eles têm em comum deve apenas fazer sentido a partir do conceito nãoestético de delicadeza. Isso porque os elementos de disjunção são bastante diversos - uma verdadeira confusão. Não é plausível que essa disjunção seja uma disjunção natural ou que

\footnotetext{
${ }^{9}$ Ao tentar localizar um exemplo convincente, fiquei bastante surpreso ao descobrir a diminuta quantidade de músicas para piano de Chopin que poderiam encaixar-se nessa descrição.
} 
ela figure de maneira fundamental em nossas experiências estéticas. Apenas o conceito não-estético fornece algum princípio de unidade para o conjunto heterogêneo de propriedades estéticas reunidas sob o conceito estético geral de delicadeza. Daí a razão pela qual não nos é possível adquirir aqueles conceitos estéticos relativamente indeterminados sem possuir, ou sem que já tenhamos possuído, o conceito nãoestético correspondente. (Essa é a explicação buscada por Budd para o caso dos conceitos estéticos gerais). A posse de um é, de fato, uma condição necessária para a posse do outro. Mas isso não se aplica aos conceitos estéticos determinados que são fundamentais em termos de explicação.

E se alguém negasse tanto a existência de propriedades estéticas determinadas, como também o fato de que as representamos na experiência? De acordo com esse ponto de vista, nós identificamos demonstrativamente propriedades não-estéticas complexas (tais como padrões complexos disponíveis visualmente ou auditivamente), e nós representamos aquelas propriedades não-estéticas como a incorporação de propriedades estéticas gerais (tais como a delicadeza genérica), mas não como representação de propriedades estéticas determinadas. A questão posta é: por que pensar que representamos propriedades estéticas determinadas somadas às propriedades não-estéticas determinadas e às propriedades estéticas gerais? Quão 'refinada' é nossa vida estética? Em resposta, consideremos a delicadeza em nuvens, em música e em poesia. É plausível que elas sejam três propriedades estéticas diferentes de delicadeza, e que, portanto, nós tenhamos três diferentes conceitos de delicadeza para pensá-las. Não existem apenas três diferentes maneiras não-estéticas de gerar delicadeza genérica - pela aparência visual, pelos sons e pelas palavras. 0 que cada uma gera é uma delicadeza diferente. Contudo, suponhamos que o ceticismo negasse isso de maneira instransigente e insistisse que o único conteúdo estético representacional seria uma delicadeza genérica, e não três tipos de delicadeza estética. Um argumento poderia ser o seguinte: a experiência estética fundamenta o prazer estético. Se existisse apenas um conceito estético em jogo (a saber: a delicadeza genérica), então a resposta prazerosa nos três casos deveria ser a mesma. Mas o 
prazer estético na delicadeza da aparência visual, dos sons e das palavras é muito diferente. Consequentemente, os conceitos em jogo nas experiências estéticas são também diferentes. Além disso, o que vale para as três delicadezas também vale para discriminações mais sutis dentre os conceitos estéticos. Uma consideração mais teórica é a de que o realismo em qualquer área (exceto em casos especiais, como a matemática) aceita uma visão não-esparsa das propriedades em questão. Seria bastante estranha a ideia de que poderíamos ser realistas a respeito de propriedades genéricas em certos domínios, mas não a respeito de propriedades desse tipo, determinadas de maneira mais sutil. Tipicamente, as propriedades realistas permanecem em um contínuo ou são determinadas por propriedades daquele tipo que permanecem em um contínuo (exceto em casos especiais, como na matemática). Portanto, o ceticismo sobre propriedades estéticas determinadas, ao mesmo tempo em que se adotam as propriedades estéticas genéricas constitui uma combinação 78 desconfortável.

$\S 2.7$ A queixa de Budd era a de que o realismo implica numa certa possibilidade, a saber: a de possuir o conceito estético sem possuir o conceito não-estético. A resposta a essa queixa é: no que diz respeito a conceitos estéticos determinados, o realista pode considerar que esse pensamento de Budd é algo problemático. Simplesmente não é verdade que a posse de um conceito estético determinado e que representa uma propriedade estética determinada (que é sinalizada por meio de uma palavra usada metaforicamente), requeira a posse do conceito que a palavra geralmente expressa quando utilizada em seu sentido literal. 0 realista nega que a aquisição daquele conceito estético determinado precise passar pelo conceito não-estético, e a afirmação de Budd de que existe essa necessidade é uma falácia (petitio principii) e é insustentável. Mesmo assim, não é implausível que a aquisição de conceitos estéticos mais gerais deva passar pela posse de conceitos nãoestéticos gerais. Assim, se um conceito estético refere-se a uma propriedade estética geral, e se nós descrevemos metaforicamente aquela propriedade estética por meio de uma palavra que expressa literalmente um conceito não-estético que se refere a uma propriedade não-estética, então nós 
poderíamos ter adquirido o conceito estético sem possuir primeiramente o conceito não-estético. Porém, não existe motivo para pensar que isso seja plausível. De qualquer modo, a visão estética realista não é problemática.

\section{§ 3. Descrição Metafórica e Conceitos Estéticos}

§ 3.1 Dada a distinção entre conceitos estéticos e nãoestéticos e a consideração de relação causal acerca da conexão entre eles, pergunta-se: como devemos compreender uma descrição linguística metafórica de propriedades estéticas (descrições que empregam palavras que normalmente se referem a propriedades não-estéticas)? Em particular, como devemos explicar a razão pela qual certas palavras usadas para designar propriedades não-estéticas sejam apropriadas para descrições metafóricas de propriedades estéticas? E ainda: como o significado não-estético de palavras figura no uso de metáforas estéticas? Postular relações causais entre conceitos estéticos e não-estéticos, por si só, não responde a essas questões ${ }^{10}$. Budd escreve:

(...) as pretensas conexões causais não fornecem uma explicação satisfatória do uso da mesma palavra para a propriedade estética e para a qualidade não-estética correspondente (BUDD, 2008, p. 178).

(...) o pretenso fato de que a posse de um conceito é causalmente dependente da posse de outro conceito (...) não faz da palavra usada no segundo conceito uma metáfora apta para o primeiro, e muito menos a mais apropriada ou a mais natural delas (BUDD, 2008, p. 178).

Uma pequena contestação poderia ser a de que essa crítica não chega a ser uma objeção, mas sim, uma demanda por mais informação. É verdade que a consideração de causalidade

10 Se a Tese da Metáfora Essencial (Essential Metaphor Thesis) é verdadeira, isso explica porque somos levados a usar metáforas de algum tipo para descrever música, mas isso não explica as metáforas particulares que usamos. 
não explica o motivo pelo qual, dentre muitas metáforas possíveis que poderíamos utilizar para descrever a música, geralmente escolhemos empregar palavras para emoção, movimento ou altura, em particular. É verdade que ainda há muita coisa a ser dita para explicar por que, tanto em casos gerais, como em casos particulares, tais metáforas são usadas para descrever a música. Contudo, fornecer tal explicação poderia ser um objetivo demasiadamente ambicioso. Naturalmente, seria muito interessante dispor de tal explicação. Mas alegar que a tese fundamental - de que existe uma conexão causal entre a posse de conceitos estéticos e nãoestéticos - não proporciona essa explicação ambiciosa, não constitui uma objeção válida. Diante dessa alegação, a consideração de causalidade poderia ser complementada com mais explicações. A consideração de causalidade poderia ser apenas parte de uma consideração ideal inteiramente satisfatória, e que nos diga por que toda descrição metafórica apropriada é apropriada. Mesmo faltando essa 80 complementação, ainda assim é verdade que a consideração de causalidade proporciona uma defesa contra a objeção de que na consideração realista não poderia existir nenhuma conexão entre os dois conceitos.

§ 3.2 Será que o esteta realista deve uma explicação acerca de todas as metáforas apropriadas que utilizamos na descrição musical? Eu diria que isso é pedir demais, por ao menos três motivos.

Primeiramente, os não-realistas também têm de lidar com a dificuldade da explicação com descrições metafóricas. Dado o estado mental que os não-realistas postulam como constitutivos da experiência musical, não é óbvio como as metáforas que usamos se relacionam àqueles estados mentais. Portanto, não são apenas os realistas que possuem dificuldades nas suas explicações. 0 que precisa ser argumentado, porque não é algo óbvio, é que os não-realistas têm, nesta questão, uma vantagem nas suas explicações em relação aos realistas.

Em segundo lugar, não há motivo para se esperar uma explicação única e que abarque todos os casos. Há uma grande variedade de descrições metafóricas da música. Uma explicação da adequação da música em termos da emoção é tão 
inapropriada quanto a explicação da adequação da descrição da música em termos de clima, trânsito ou conversação. Diferentes descrições metafóricas exigem diferentes explicações. Além disso, como em toda descrição metafórica, a descrição metafórica da música possui um aspecto criativo, que nos obriga a transpor os limites de uma teoria geral. Deveríamos, portanto, permanecer céticos quanto à possibilidade de busca por qualquer teoria unitária ${ }^{11}$.

Em terceiro lugar, o fato de que algumas metáforas sejam tidas como apropriadas e outras como inapropriadas parece ser uma questão da psicologia empírica. Aqui, a filosofia tem apenas que remover a ideia equivocada de que nenhuma explicação seria possível. Para o realista, é um fato psicológico bruto que certas metáforas causem certos pensamentos; e a efetividade da metáfora (que pode variar de acordo com a cultura e também de pessoa para pessoa) depende de tais fatores psicológicos. Suponhamos que alguém descreva processos econômicos ou geológicos em termos metafóricos (talvez em termos de "mãos" e "placas"). Nesses casos, as características estruturais causais das coisas que as palavras representam literalmente correspondem a características estruturais causais dos processos econômicos ou geológicos, de maneira a tornar apropriada a metáfora. Graças a esses isomorfismos estruturais, essas metáforas podem transmitir conhecimentos de economia ou de geologia. 0 caso da música

11 Ver também Zangwill (2010b, p. 1-4). Em um ponto Budd parece estar argumentando que o realista musical pensa que existe apenas uma metáfora para descrever uma propriedade estética (BUDD, 2008, p. 178). Mas isso seria uma visão estranha para um realista. A concepção realista é, ou deveria ser, uma visão pluralista - a de que nenhuma propriedade estética descrita em termos metafóricos (como uma metáfora de emoção), poderia também ser apropriada se descrita por outras metáforas, tais como metáforas de clima ou de trânsito. 0 que não pode ser substituído são algumas descrições não-metafóricas. Diferentes metáforas são mais ou menos apropriadas para uma realidade que, em última análise, desafia a descrição literal. Algumas questões e problemas similares prejudicam o argumento de Malcolm Budd. A esse respeito, cf. BUDD (1985, p. 16-36), especialmente a seção 13 do segundo capítulo. 
por vezes é assim, mas por vezes, não. Às vezes, existem analogias estruturais. Mas geralmente é mais como o caso de descrições metafóricas de sensações ou estados de espírito. Por exemplo, é apenas um fato da psicologia humana que a fenomenologia da depressão seja melhor descrita em termos de escuridão e peso, ao invés de seus antônimos. É preciso que nos contentemos com tais associações. A psicologia pode explorar isso, mas a filosofia não precisa ir além. Aliás, por que deveria? Não existe nenhum resquício de perplexidade que precise ser removido. Dá-se o mesmo com muitas descrições metafóricas das propriedades estéticas da música. Por que, exatamente, "triste" e "delicado" são descrições apropriadas para algumas músicas? Há uma história psicológica ainda a ser contada, mas não há nenhum problema, enigma ou paradoxo filosófico: existem propriedades estéticas da música e existe o fato psicológico de que o uso das palavras "triste" ou "delicado" chama a nossa atenção para estas propriedades estéticas. Qual o problema? Evidentemente, os não-realistas e teóricos da 82 emoção da música têm outras explicações. Mas para um realista estético há aqui apenas uma questão da psicologia experimental, e para além disso, não existe qualquer dificuldade dialética ou objeção para o realista moral no fato de que algumas descrições pareçam mais apropriadas que outras. Por que certas sensações ou estados de espírito parecem ser apropriadamente descritos em termos de algumas cores e não de outras? Podemos ter uma curiosidade psicológica a esse respeito, mas não há nenhum problema filosófico aí. 0 mesmo se dá com as descrições metafóricas da música. Naturalmente, a maneira de se criar um problema filosófico poderia ser a utilização da descrição no sentido literal. Mas, ao menos que estejamos caçando problemas, por que faríamos isso?

§ 3.3 Uma questão diferente é a necessidade de compreender como o significado ordinário não-estético de "delicadeza" guia o seu uso estético metafórico. Aproveitando um argumento de Scruton, Budd expõe a seguinte preocupação:

(...) uma compreensão do uso metafórico deve ser guiada por uma compreensão do uso literal da sentença: o significado de 'triste' usado literalmente informa a interpretação correta de seu uso estético metafórico, pois o emprego do termo 'triste' é precisamente para indicar ou expressar uma conexão entre 
música e tristeza - é precisamente para relacionar a música com a tristeza (BUDD, 2008, p. 179).

A ideia de que o significado literal "informa" metáforas é plausível, contudo eu prefiro fazer uma distinção entre "significado literal" e "uso metafórico". É claro que o significado literal é aquele empregado no uso metafórico da palavra. Eu não tenho certeza do quanto ao significado literal limita o uso metafórico, mas ele certamente o restringe, e por isso ele é usado. Tal como um pote é feito de argila e uma casa é feita de tijolos, também uma metáfora é feita do sentido literal. Portanto é claro que o sentido literal restringe o uso metafórico. As noções de "guiar" ou "informar" usadas na citação acima podem implicar esses tipos de restrições, que são comuns a todas as metáforas, uma vez que ela são feitas de palavras com significado literal. Por exemplo, o significado literal de palavras que expressam cores, nesse sentido, "guiam" e "informam" seus usos metafóricos na descrição de estados de espírito e emoções. Algo similar ocorre com o significado literal das palavras "triste" e "delicado" e o uso metafórico das mesmas na descrição da música e de experiências musicais.

Contudo, se seguirmos dizendo que o significado literal (Budd diz "o uso") de "triste" e o uso metafórico de "triste" são conectados pela relação entre a música e a emoção real, isso não é mais aceitável de forma neutra, e isso é problemático por, pelo menos, duas razões diferentes. Primeiramente, isso se torna uma petitio principii se supormos ser um argumento contrário à interpretação do realista acerca da descrição metafórica. Em segundo lugar, isso é intrinsecamente implausível. Por exemplo, quando descrevemos um estado de espírito como "negro", isso com certeza não acontece porque vislumbramos uma relação entre o sentimento e a cor. (O cérebro de uma pessoa depressiva é mais escuro que o cinza usual?). A afirmação sobre música e tristeza é dialeticamente tendenciosa e intrinsicamente implausível como uma teoria geral.

$\S 3.40$ fato de que haja uma diferença entre os dois conceitos é compatível com algum tipo de relação-guia, ou talvez uma relação que os restrinja, ligando o sentido literal de palavras não-estéticas com o seu uso estético metafórico. Como 
vimos, a afirmação da existência de uma relação causal entre a posse dos dois conceitos não explica, por si só, a relação entre significados literais e usos metafóricos. Contudo, a relação causal não é incompatível com algum tipo de relação desse tipo. $\mathrm{Na}$ verdade, poderíamos esperar que alguma relação causal entre os conceitos seja uma parte necessária de uma relação plausível de guiamento (guiding). Quando um cão guia uma pessoa cega, existe uma relação causal entre o cão e a pessoa. Existe muito mais que isso, mas a relação causal é parte disso.

Realistas e não-realistas possuem explicações diferentes sobre o fenômeno de guiamento. Ambos os lados deverão concordar que o sentido literal não-estético da palavra guia, ou pelo menos restringe, o seu uso estético não-literal. Contudo, para o realista estético, um conceito guia o outro porque o significado literal da palavra conduz a pessoa que recebe a metáfora a experienciar e a pensar sobre a propriedade estética que se pretendia indicar, ou para a qual 84 pretendia-se chamar nossa atenção, pelo uso não-literal da palavra ${ }^{12}$. Por outro lado, para um esteta não-realista, tal como Scruton, os sentidos não-estéticos guiam seus usos estéticos porque o significado literal indica qual ato imaginativo está supostamente envolvido na percepção do aspecto estético: é o ato imaginativo que desenvolve o conceito que é tipicamente expresso no uso literal da palavra. Contudo, para Scruton, aquele conceito não é "assertivo", por assim dizer, ou adequado para aplicação às coisas (Cf. SCRUTON, 1974; 1997; 2004, p. 184-187). Outros não-realistas podem ter outras explicações ${ }^{13}$.

12 Davidson fala de como as metáforas podem nos fazer "apreciar algum fato" e ele fala de "[...] para o que a metáfora chama nossa atenção" (DAVIDSON, 1984, p. 262-263).

13 O literalista é o teórico que tem um problema maior com o guiamento - mais do que o realista ou o não-realista scrutoniano. 0 literalista pensa, por exemplo, que em nossas descrições emotivas da música, nós estamos atribuindo relações entre a música e as emoções reais. Contudo, nossa experiência imediata da música é a das características da música que são experienciadas como nãorelacionais ou intrínsecas. Portanto, na teoria literalista, o significado literal usual de palavras como "triste" nos conduz a um erro: trata-se mais de uma desorientação que de uma orientação! 
$\S 3.5$ Pode parecer que seja um problema determinar como, numa consideração realista do uso da metáfora, a plateia chega até o pensamento estético exato que se supunha que ela teria. Será que a interpretação da metáfora, para o realista estético, é apenas um salto no escuro? A resposta é afirmativa, até um certo ponto. 0 significado literal é, de certa forma, uma espécie de guia, na medida em que temos a disposição para associar sentidos literais a propriedades estéticas, mas isso deixa muita coisa em aberto; e uma pessoa entende o que outra quer dizer desde que elas compartilhem experiências estéticas de música. Se uma pessoa entende a descrição metafórica de outra, então elas ouvem a música como portadora (de alguma maneira) de propriedades estéticas similares. Porém, se elas têm experiências musicais muito diferentes, então é apenas uma contingência da vida que elas talvez possam não entender as metáforas uma da outra. Na interpretação de metáforas, o problema das outras mentes constitui um problema real

O problema que orienta a concepção não-realista de Scruton é menos interessante quando o significado usual da palavra expressa o conceito que se pretende que seja imaginado, mas não aplicado. Quando recebemos a instrução efetiva: "Use aquele conceito em seu ato imaginativo". O sentido literal indica qual ato imaginativo poderia ser. Podemos imaginar, por exemplo, que a música é delicada ou triste, ou que ela mantém alguma relação com a delicadeza ou a tristeza. Poderia se dizer que a interpretação de metáforas estéticas gera um problema das outras mentes (other-minds problem) para o realista, mas esse problema não aparece para o não-realista e, por isso, essa seria uma razão para preferirmos o não-realismo. A réplica a essa objeção é que o problema da mente dos outros é, às vezes, um problema real, e não apenas um exercício acadêmico - e, portanto, nesses casos, é melhor para a teoria preservar tais problemas em alguma medida. Trata-se de um bom problema (e não de um mau problema). Havendo convergência nas experiências, nós podemos interpretar as metáforas estéticas de outras pessoas; porém, faltando convergência nas experiências, tais interpretações podem ser difíceis ou impossíveis. A convergência na interpretação, para o realista, acontece porque aquilo que a metáfora possibilita que os ouvintes percebam ou pensem é o 
mesmo ou algo similar. Ou ainda: os interlocutores já experienciam a música de modo similar e, assim, tomam a metáfora de modos similares. Se uma pessoa irá ou não compreender a descrição metafórica da música feita por outra pessoa, isso irá depender do fato contingente de que as suas experiências musicais sejam similares às do interlocutor. Essa é uma base frágil para a compreensão das descrições linguísticas uns dos outros, mas essa base frágil é tudo o que temos.

\section{Conclusão}

0 realismo estético tem muitas vantagens. Uma delas é a possibilidade de explicar facilmente algumas características importantes de nossos julgamentos estéticos a respeito da música, tais como as suas aspirações à exatidão, uma vez que as propriedades estéticas são a fonte de correção e incorreção (cf. ZANGWILL, 2003). O realista estético interpreta muitas 86 descrições de música como descrições metafóricas de propriedades estéticas da música. Uma vez que as palavras usadas em descrições metafóricas têm apenas um sentido literal, o realismo estético requer que as palavras não-estéticas sejam usadas para expressar tanto conceitos estéticos quanto conceitos não-estéticos. Tendo distinguido os conceitos, algumas considerações plausíveis devem ser feitas acerca de suas relações. A consideração causal da relação entre a posse de conceitos estéticos e não-estéticos proporciona isto, uma vez que os conceitos são distintos, mas conectados. Se isso significa que alguém pode possuir conceitos estéticos sem possuir o correspondente conceito não-estético, então que assim seja. Pelo menos, isso não é implausível para conceitos estéticos determinados, mesmo que isso não seja verdade para muitos conceitos estéticos gerais. Além disso, existe uma consideração plausível de descrições metafóricas que acompanham a concepção de conceitos estéticos e conceitos não-estéticos; as palavras literais para propriedades nãoestéticas são apropriadas e usadas para chamar a atenção para as propriedades estéticas. Os detalhes exatos de como isso acontece e do motivo pelo qual algumas metáforas são mais apropriadas que outras é um problema da psicologia empírica, e não uma questão filosófica. 
Acredito que o realismo estético nos ofereça uma abordagem convincente. Nossa experiência musical é direcionada às propriedades estéticas da música, as quais por vezes experienciamos com deleite ${ }^{14}$. Essa é a realidade à qual nossos conceitos estéticos se referem e essa é a realidade que nós procuramos - embora imperfeitamente - descrever usando metáforas ${ }^{15}$.

\section{Referências bibliográficas}

BUDD, Malcolm. Music and Emotions. London: Routledge, 1985. Aesthetic Essays. Oxford: Oxford University Press, 2008.

DAVIDSON, Donald Donald. What Metaphors Mean. In: Inquiries into Truth and Interpretation, Oxford: Clarendon, 1984. (Originalmente publicado em Critical Inquiry 5, 1978, p. 31-47).

DAVIES, Stephen. Musical Meaning and Expression. Ithaca: Cornell, 1994.

GEACH, Peter. Mental Acts, London: Routledge, 1957.

LEVINSON, Jerrold. Musical Expressiveness. In: The Pleasures of Aesthetics, Ithaca: Cornell, 1996.

Musical Expressiveness as Hearability-as-Expression. In: Contemplating Art. Oxford: Oxford University Press, 2006.

SCRUTON, Roger. Reply to Budd. In: British Journal of Aesthetics. Oxford: Oxford Journals, v. 44, n. 2, 2004, p. 184-187.

${ }^{14}$ Isso pode parecer, num bom exemplo, como se o resto do mundo não existisse e como se nós habitássemos um mundo de sons - um universo auditivo do tipo imaginado por Peter Strawson (1959, cap. 2 ), com objetos e acontecimentos auditivos, assim como, propriedades auditivas - ou, talvez, pareceria que nossa mente é constituída por aqueles sons. Cf. ainda (SCRUTON, 1997, capítulo 1).

15 Esse artigo foi apresentado na Escola de Pesquisa de Ciências Sociais de Camberra, em La Trobe University e na Escola de Estudos Avançados da Universidade de Londres. Agradeço àqueles que levantaram questões naquelas ocasiões. 
1997.

The Aesthetics of Music. Oxford: Oxford University Press. . Art and Imagination. London: Methuen, 1974;

STRAWSON, Peter. Individuals. London: Methuen, 1959.

ZANGWILL, Nick. Metaphor as Appropriation. In: Philosophy and Literature, Baltimore: Johns Hopkins University Press, v. 38, n 1, 2014, p. $142-152$.

Moral Metaphor and Thick Concepts: What Moral Philosophy Can Learn from Aesthetics. In: KIRCHIN, Simon (ed.) Thick Concepts. Oxford: Oxford University Press, 2013.

. Music, Essential Metaphor and Private Language. In: American Philosophical Quarterly. Illinois: University of Illinois Press, v. 48, n. 1,2011 , p. 1-16.

. Scruton's Musical Experiences. In: Philosophy. Cambridge: Cambridge Journals Online, v. 85, n. 1, 2010a, p. 91-104.

88 Aesthetic. Aaehus: Aarhus University Press, v. 20, n. 38, 2010 b.

Appropriate Musical Metaphors. In: Nordic Journal of . Music, Metaphor and Emotion. In: Journal of Aesthetics and Art Criticism. New York: Wiley, v. 65, n. 4, 2007, p. 391-400.

Against Emotion: Hanslick was Right about Music. In: British Journal of Aesthetics. Oxford: Oxford Journals, v. 44, n. 1, 2004, p. 29-43.

Aesthetic Realism. In: LEVINSON, Jerrold (ed.) Oxford Companion to Aesthetic. Oxford: Oxford University Press, 2003.

. Metaphysics of Beauty. Ithaca: Cornell University Press, 2001.

. Metaphor and Realism in Aesthetics. In: Journal of Aesthetic and Art Criticism. New York: Wiley, v. 49, n.1, 1991, p. 57-62. (reimpresso em ZANGWILL, Nick. Metaphysics of Beauty, 2001) 